\title{
IMPACT OF SMOKING ON METABOLIC CHANGES AND EFFECTIVENESS OF DRUGS USED FOR LUNG CANCER
}

\author{
František Perlík ${ }^{1,2}$ \\ ${ }^{1}$ Department of Pharmacology, First Faculty of Medicine, Charles University and General University Hospital, Prague, Czech Republic \\ ${ }^{2}$ Institute for Postgraduate Medical Education, Prague, Czech Republic
}

\section{SUMMARY}

Objective: This article reviews the published studies dealing with the influence of cigarette smoking on metabolic changes and effectiveness of drugs used in the systemic chemotherapy of the lung cancer.

Methods: The literature search of interactions between cigarette smoking and drugs used for lung cancer was carried out. The abstracted data mostly involved some induction of key drug-metabolizing enzymes of cytochrome CYP1A1/2, CYP2D6, CYP3A4 and isoforms of UDPglucuronosyltransferase.

Results: Metabolic changes are important both in the non-chemotherapy and for the drugs used in the chemotherapy. They can change pharmacokinetic and pharmacodynamic effects of drugs. Primarily, we addressed potential differences in drug effects on smokers and non-smokers. The increased clearance of erlotinib and irinotecan may have impact on effectiveness of the lung cancer therapy. The effects of taxanes and gemcitabine are more complex.

Conclusion: The evaluated studies show that continued smoking after lung cancer diagnosis is related to poor prognosis, reduced survival, risk of second primary malignancies, and increased cancer recurrence. Of particular importance is the deterioration in the quality of life and an increased incidence of the adverse drug reactions in smokers. The patient's cigarette smoking history should be considered carefully and smoking cessation must be taken into account.

Key words: cigarette smoking, lung cancer, chemotherapy, cytochrome P450

Address for correspondence: F. Perlík, Department of Pharmacology, First Faculty of Medicine, Charles University and General University Hospital, Albertov 4, 12800 Praha 2, Czech Republic. E-mail: fper|@lf1.cuni.cz

https://doi.org/10.21101/cejph.a5620

\section{INTRODUCTION}

Tobacco smoke is the leading preventable cause of cancer development. Despite anti-smoking campaigns, cigarette smoking remains highly prevalent in most countries. With $29 \%$ (24\% of men, $18 \%$ of women), the prevalence of smoking remains high in the Czech Republic (1).

Among various biological effects, cigarette smoke contains several chemical constituents that can interact with drug metabolizing enzymes. These enzymes are important in drug metabolism and/or in the activation of procarcinogens. It can affect drug therapy both by pharmacokinetic and by pharmacodynamic mechanisms. The induction of drug-metabolizing enzymes is important for pharmacokinetic interactions with consequences for the concurrent drug therapy both for non-chemotherapy and for chemotherapy used drugs. The chemicals in smoke may interact by increasing the clearance of antipsychotics, antidepressants, benzodiazepines, oral contraceptives, and inhaled corticosteroids. Nicotine in smoke may cause pharmacodynamic interaction associated with reduced beta-blocker effectiveness, i.e. by lowering blood pressure and heart rate (2). The impact of smoking on the effects of drugs used in chemotherapy of cancer patients has also been repeatedly investigated. This review summarizes the effect of cigarette smoking on the metabolic changes and effectiveness of drugs used in systemic chemotherapy for lung cancer.

\section{Effects of Cigarette Smoking on Metabolism}

In addition to the carcinogenic effects of tobacco products, the components of cigarette smoke can induce drug-metabolizing enzymes. The best characterized are polycyclic aromatic hydrocarbons that induce mainly but not only several isoforms of cytochrome P450 enzymes (CYP). The induction of CYP, which normally process xenobiotics, may accelerate clearance of chemotherapeutics and reduce drug efficacy in the smokers, with impact on the clinical outcome. The most common isoforms of CYP related to the metabolism of often used systemic therapy for lung cancer include CYP1A1/2, CYP2D6, CYP3A4 and some isoforms of UDP-glucuronosyltransferase $(3,4)$.

The CYP1 family comprises three members, namely CYP1A1, 1A2, and 1B1. The CYP1A1 is mainly extrahepatic in humans and is found in lung and placenta (5). The CYP1A2 is one of the major CYPs in the human liver. This enzyme metabolizes about $15 \%$ of drugs such as clozapine, theophylline, tacrine, and zol- 
mitriptan. CYP1 family members are the most common isoforms that metabolize some systemic therapies used to treat lung cancer such as erlotinib (3).

The CYP1A2 is also a major enzyme that bioactivates some procarcinogens and metabolizes several endogenous compounds such as steroids and arachidonic acids, which have an important role in some physiological processes. Cigarette smoking is wellestablished inducer of the CYP1A2 activity (6).

Induction of CYP1A2 is linked to increased activity of the enzyme, which in turn leads to reduced serum concentrations and reduced efficacy of the substrates. CYP1A2 activity is significantly higher in heavy smokers (more than 20 cigarettes/day) than in nonsmokers. Genetic polymorphisms of the CYP1A2 gene contribute to extensive inter-individual variability in the drug metabolism and may favour cancer development and spread (7). They are associated with altered inducibility of gene expression in smokers and are also responsible for marked ethnic differences in the distribution of CYP1A2 mutations. This means that different ethnic groups could respond differently (8).

A more detailed information on the effects of the cigarette smoke constituents on the drug-metabolising enzymes, the molecular basis for such effects, and the clinically important ways in which cigarette smoking affects drug action were described by Zewin and Benowitz (9).

CYP2D6 is an important member of cytochrome P450 enzymes. Its relative content in the non-induced human liver is about $4 \%$ of all cytochrome P450 enzymes (10). Despite its small percentage, the role of CYP2D6 in the drug metabolism is extensive. The major drug substrates include, for example, tricyclic antidepressants, serotonin reuptake inhibitors, neuroleptics, beta-blockers, and antiemetics. This enzyme has been reported to have multiple single-nucleotide polymorphisms (SNPs) that can lead to varying expression among the population. These different SNPs are associated with specific phenotypes, namely, extensive metabolizers, ultra-rapid metabolizers, and slow metabolizers. The distribution of variant alleles of CYP2D6 in the Czech population are in concordance with other Caucasian populations (11).

CYP3A4 is apparently the most important P450 enzyme for drug metabolism in humans. This is not only because of its amount in the liver and gut which may be increased by induction to more than $60 \%(10)$. It is responsible for metabolism of more than $50 \%$ of the prescribed drugs, wherein, several of them are used for systemic therapies for lung cancer. They comprise taxanes, gefitinib, and erlotinib. This increase in transcription leads to increased activity of the enzymes, which in turn can affect pharmacokinetics of those drugs that are metabolized by the CYP3A4 isoform (12).

In most human tissues, UDP-glucuronosyltransferases are expressed in a tissue-specific and frequently inducible way. They contribute to about $35 \%$ of phase II drug metabolism and are involved in the glucuronidation of many endogenous compounds and xenobiotics (13). Polycyclic aromatic hydrocarbons are known to induce some isoforms of the UDP-glucuronosyltransferase family, which includes phase II drug-metabolizing enzymes being responsible for glucuronic acid conjugation. Studies have shown increased glucuronidation rates of drugs such as codeine and propranolol in smokers. Recently, the UDP-glucuronosyltransferase gained recognition as the first pharmacogenomic test to achieve FDA approval for use in conjunction with irinotecan.

\section{Pharmacokinetic and Pharmacodynamic Effects of Chemotherapeutic Drugs Related to Smoking}

Here, we examine the main interactions of tobacco smoke with the drugs often used in systemic therapy for lung cancer. We primarily address the potential differences in the drug metabolism in smokers versus nonsmokers.

\section{Erlotinib}

Erlotinib is a selective inhibitor of the epidermal growth factor receptor (EGFR) tyrosine kinase and inhibits proliferation of tumor cells in vitro. The use of erlotinib in advanced lung adenocarcinoma is currently approved for patients with an activating EGFR mutation. A small subset of patients with wild-type EGFR genes may also respond to erlotinib. However, for this group of patients, the observed improvement was not as great as in the patients with EGFR mutations. Erlotinib is predominately metabolized by CYP3A4 and to a lesser extent by CYP1A2 and CYP1A1 enzymes. The question whether decreased erlotinib exposure was seen in current smoking cancer patients versus former or never smokers was investigated by Hamilton et al. (14).

Current smokers achieved significantly lower erlotinib exposure following a single 150 or $300 \mathrm{mg}$ dose than the nonsmokers. Following the $150 \mathrm{mg}$ dose, the geometric mean erlotinib area under the concentration curve (AUC) in smokers was 2.8-fold lower than in nonsmokers and similar to that of nonsmokers at the 300 mg dose. $C_{\max }$ in smokers was two-thirds of that in nonsmokers, and $C_{24 \mathrm{~h}}$ in smokers was 8.3-fold lower than in the nonsmokers. The median $C_{24 \mathrm{~h}}$ of smokers at the $300 \mathrm{mg}$ dose was slightly less than the $C_{24 \mathrm{~h}}$ of smokers at the $150 \mathrm{mg}$ dose. The median $C_{\max }$ was greater in smokers at the $300 \mathrm{mg}$ dose than in the nonsmokers at the $150 \mathrm{mg}$ dose. This study confirms that the pharmacokinetics of erlotinib differs between current smokers and nonsmokers. The observation that $\mathrm{AUC}_{0-\infty}$ and $C_{24 \mathrm{~h}}$ were significantly decreased in smokers compared with nonsmokers, and a smaller decrease in $C_{\max }$ was observed, is consistent with increased metabolic clearance of erlotinib in the current smokers.

Several studies summarized in a review by O'Malley et al. (4) show that smoking alters the pharmacokinetics of erlotinib, with decreased plasma concentrations and increased clearance in the smokers. It has been hypothesized that these findings may be due, in part, to induction of the cytochrome P450 CYP1A1 and CYP1A2 isoforms by the cigarette smoke, leading to increased catabolism and clearance. This has important clinical implications. The nonsmokers had a higher incidence of adverse events, possibly indicating increased erlotinib exposure compared with the smoker cohort. The most crucial intervention is smoking cessation. However, one must take into consideration the altered pharmacokinetics of erlotinib in the patients who have recently quit smoking, yet still demonstrate increased CYP induction (15-17).

\section{Taxanes}

Both docetaxel and paclitaxel are antimicrotubule agents metabolized by CYP3A and CYP2C8. They are used as a first-line treatment of non-small-lung cancer (NSCLC), often with a platinum compound. The effects of smoking on the pharmacokinetic variables and toxicity profiles of both docetaxel and paclitaxel were studied by de Graan et al. (18).

The authors conducted a retrospective study of patients with advanced non-small-cell lung carcinoma (NSCLC) enrolled 
in multiple trials involving drug concentration analyses. The smoking status, toxicity profiles, and pharmacokinetic parameters (calculated by nonlinear mixed-effect modeling population analysis) were determined in 566 patients treated with docetaxel or paclitaxel. Smokers treated with docetaxel showed less grade IV neutropenia ( $35 \%$ vs. $52 \%, p=0.010)$ than nonsmokers. Smokers treated with paclitaxel had less grade III-IV leukopenia than nonsmokers $(12 \%$ vs. $25 \%, \mathrm{p}=0.030)$, and the white blood cell (WBC) nadir was lower in nonsmokers (median: $2.7 \cdot 10^{9} / \mathrm{L}$; range: $0.05 \cdot 10^{9}$ to $11.6 \cdot 10^{9} / \mathrm{L}$ ) than in smokers (median: $3.3 \cdot 10^{9} / \mathrm{L}$; range: $0.8 \cdot 10^{9}$ to $\left.10.2 \cdot 10^{9} / \mathrm{L} ; \mathrm{p}=0.020\right)$. Of interest, significantly lower WBC counts and absolute neutrophil counts at baseline were seen in nonsmoking patients treated with paclitaxel $(p<0.001)$. Pharmacokinetic parameters were similar in smokers and nonsmokers for both taxanes. The results show that cigarette smoking does not alter the pharmacokinetic determinants of docetaxel and paclitaxel; nevertheless, smokers treated with docetaxel and paclitaxel have less neutropenia and leukopenia.

\section{Irinotecan}

Irinotecan is a substrate for several cytochrome P450 and UGT1A1 isoenzymes, which are known to be induced by tobacco smoke. The potential clinical effects of smoking on irinotecan pharmacokinetics were investigated by van der Bol et al. (19).

The authors reviewed the data of 190 patients who received irinotecan (90-minute intravenous administration on a 3 -week schedule) through nine prospective trials. In smokers, the dosenormalized area under the plasma concentration-time curve of irinotecan was significantly lower (median: 28.7 vs. $33.9 \mathrm{ng}$ $\cdot \mathrm{h} / \mathrm{mL} / \mathrm{mg}, \mathrm{p}=0.001)$ compared with nonsmokers. In addition, smokers showed an almost $40 \%$ lower exposure to SN-38 (median: 0.54 vs. $0.87 \mathrm{ng} \cdot \mathrm{h} / \mathrm{mL} / \mathrm{mg}, \mathrm{p}<0.001$ ) and a higher relative extent of glucuronidation of SN-38 into SN-38G (median: 6.6 vs. $4.5, p=0.006$ ). Smokers experienced considerably less hematologic toxicity. In particular, the incidence of grade 3 to 4 neutropenia was $6 \%$ in smokers versus $38 \%$ in nonsmokers (OR $0.10,95 \%$ CI $0.02-0.43, p<0.001)$. This study indicates that smoking significantly lowers both the exposure to irinotecan and treatment-induced neutropenia, indicating a potential risk of treatment failure.

\section{Gemcitabine}

Gemcitabine is a prodrug, a deoxycytidine analogue that requires intracellular uptake and phosphorylation to be activated. This nucleoside analogue exhibits cytotoxic effects through inhibition of DNA synthesis. Gemcitabine is inactivated by cytidine deaminase to the inactive metabolite. The overexpression of cytidine deaminase induced by smoking may lead to increased catabolism and reduced efficacy of gemcitabine in smokers and former smokers.

Kanai et al. (20) investigated the correlation between smoking history and gemcitabine-induced neutropenia in 103 patients treated with gemcitabine for different types of cancer.

There was a significantly higher incidence of grade 3-4 neutropenia among patients without a history of smoking $(55.7 \%)$ than among those with a history of smoking (23.6\%, including current and ex-smokers) (OR 0.244, 95\% CI 0.105-0.569, p < $0.001)$. The authors analyzed the correlation between gemcitabineinduced neutropenia and various clinical factors, Logistic regres- sion analysis identified a history of smoking as an independent inverse predictor of gemcitabine-induced neutropenia (OR 0.188 , $95 \%$ CI $0.057-0.618, p=0.006$ ). Patients without a history of smoking may be at higher risk of developing gemcitabine-induced neutropenia.

\section{Nicotine}

As a main component of smoke, nicotine is primarily metabolized to cotinine by CYP2A6. Variability of metabolism rate contributes to susceptibility to tobacco dependence, response to smoking cessation treatment, and lung cancer risk. In liver, nicotine is extensively metabolized by several enzymes including the CYP2A6, the aldehyde oxidases and the uridine 5'-diphosphateglucuronyl transferases. Various drugs that use these metabolic pathways can have an effect on nicotine metabolism as reviewed by Hukkanen et al. (21). Cotinine, the main metabolite of nicotine, has been shown to be a reliable marker of nicotine exposure and is more reflective of recent rather than acute nicotine use. The effect of smoking on hepatic enzymes is not related to the nicotine component of tobacco. However, there may be a direct effect of nicotine on molecular effectors of cellular apoptosis induced by several chemotherapies for lung cancer.

Nicotine is not a carcinogen, but together with its metabolites that occur during the burning process it could support tumor growth (22). It can upregulate the expression of some growth factors, such as TGF1, VEGF that are involved in neoangiogenesis, and downregulates TGF-beta, which helps tumor cells to proliferate. There is an increase in prescriptions for various forms of nicotine replacement therapies. Therefore, we looked up for studies addressing possible interactions between these therapies and the systemic chemotherapy for lung cancer. The nicotine replacement therapy does not influence the CYP1A2 activity and we did not find any human trials evaluating pharmacokinetic interactions between the nicotine replacement therapies and the systemic therapies used to treat lung cancer.

\section{Effect of Smoking Cessation on Lung Cancer Treat- ment Effectiveness}

Although the importance of smoking cessation in the primary prevention of cancer is well recognized, many cancer patients continue to smoke after diagnosis. We selected papers that have reported the smoking status and pharmacodynamic changes of drugs used for systemic therapy of lung cancer published in the period 1980-2016. The clinical impact of smoking cessation on the lung cancer treatment effectiveness is summarized in Table 1. Seven studies of our review were clinical trials with prospective design, six studies utilized retrospective data only. The results of the studies were often influenced by some methodological differences, e.g., prospective or retrospective design, histologic type of the lung cancer and its staging, smoking status, and outcomes. It is also evident that continuing or quitting smoking after the diagnosis of the malignancy could not be measured by a single parameter such as survival, course of the disease, adverse effect of therapy, and quality of life.

The results of our review could be represented by two studies that used a prospective design.

Chen et al. (23) conducted a prospective cohort study of limited-stage small-cell lung cancer (SCLC) subjects investigat- 
Table 1. Studies evaluating impact of smoking on lung cancer treatment effectiveness

\begin{tabular}{|c|c|c|c|}
\hline Study (year) & Histologic type & Study design subjects $(\mathrm{n})$ & Main results \\
\hline Johnston-Early et al. (1980) (30) & SCLC & Retrospective, chemo-radiotherapy (112) & $\begin{array}{l}\text { OS of smokers } \leq 96 \text { weeks, of non-smokers } \\
103-220 \text { weeks }\end{array}$ \\
\hline Tucker et al. (1997) (31) & SCLC & Retrospective, chemo-radiotherapy (611) & $\begin{array}{l}\text { Risk of smoking related second primary } \\
\text { cancers was } 3.5 \text {-fold }\end{array}$ \\
\hline Videtic et al. (2003) (32) & SCLC & Retrospective, chemo-radiotherapy (215) & $\begin{array}{l}5 \text {-year OS was } 8.9 \% \text { in ex-smokers, } 4 \% \text { in } \\
\text { continuing smokers }\end{array}$ \\
\hline Garces et al. (2004) (33) & SCLC & Prospective, questionnaire $(1,028)$ & $\begin{array}{l}\text { Continuing smoking negatively impacts QOL } \\
\text { score }\end{array}$ \\
\hline Johnson et al. (2005) (34) & NSCL & $\begin{array}{l}\text { Prospective randomized, FDA erlotinib review } \\
\text { (731) }\end{array}$ & $\begin{array}{l}24 \% \text { higher rate of erlotinib clearance in smok- } \\
\text { ers, better OS in never-smokers }\end{array}$ \\
\hline Shepherd et al. (2005) (35) & NSCL & Randomized double-blind, erlotinib (713) & $\begin{array}{l}\text { OS hazard ratio of smokers } 0.9(0.7-1.0) \text {, } \\
0.4(0,3-0,6) \text { of those who never smoked }\end{array}$ \\
\hline Baser et al. (2006) (36) & NSCL & Retrospective performance status (206) & Better performance status in ex-smokers \\
\hline Clark et al. (2006) (37) & NSCL & Retrospective double-blind, erlotinib (311) & In never-smokers significant benefit in OS \\
\hline Tsao et al. (2006) (38) & NSCL & $\begin{array}{l}\text { Retrospective, performance status, } \\
\text { chemo-radiotherapy }(1,370)\end{array}$ & Improved outcome in never-smokers \\
\hline Zhou et al. (2006) (24) & NSCL & Prospective, (543) & Increased OS and RFS in nonsmokers \\
\hline Chen et al. (2010) (23) & SCLC & Prospective, chemo-radiotherapy (284) & $\begin{array}{l}\text { Decreased risk of death by } 45 \% \text { in patients } \\
\text { who quit smoking }\end{array}$ \\
\hline Balduyck et al. (2011) (39) & NSCL & Prospective, lung cancer surgery (70) & Poorer post-operative QOL in current smokers \\
\hline Weiss et al. (2016) (40) & NSCL & $\begin{array}{l}\text { Clinical trial, carboplatin, pemetrexed, } \\
\text { bevacizumab (38) }\end{array}$ & $\begin{array}{l}\text { Better activity and acceptable toxicity in } \\
\text { never-smokers }\end{array}$ \\
\hline
\end{tabular}

SCLC - small-cell lung carcinoma; NSCL - non-small-cell lung carcinoma; OS - overall survival; RFS - recurrence-free survival; QOL - quality of life

ing the possible independent impact of various factors (age, sex, smoking status at the time of diagnosis, smoking cessation, performance status, treatment regimens) on survival and magnitude of the impact. Neither smoking status at the time of limited-stage small-cell lung cancer diagnosis (ex-smokers or current smokers) nor intensity (pack-years smoked) had a significant impact on the lung cancer survival. Patients who quit at or after diagnosis cut the risk of death by $45 \%(\mathrm{HR}=0.55,95 \%$ CI $0.38-0.79)$; patients who quit before lung cancer diagnosis also experienced survival benefit $(\mathrm{HR}=0.72,95 \% \mathrm{CI} 0.52-1.00)$. This study demonstrated the negative impact of continued cigarette smoking on survival; therefore, clinicians and all care providers should strongly encourage smoking cessation at the diagnosis of limited-stage SCLC.

In the study by Zhou et al. (24), 543 subjects with early-stage NSCLC were prospectively followed up after surgical resection to evaluate whether smoking cessation before diagnosis affects survival. The end points in this study were overall survival and recurrence-free survival. Smoking cessation was associated with a non-statistically significant better overall survival in the entire study population. The significantly beneficial effect of smoking cessation on recurrence-free survival or overall survival was observed only in women. The authors concluded that smoking cessation is associated with improved survival in early-stage NSCLC patients. The longer is the time since cessation of smoking, the better is the survival outcome.

The importance of smoking cessation for all cancer patients, especially those with smoking-related tumors, has been shown by Florou et al. (25). The authors demonstrated clinical importance of smoking cessation on the survival rates, quality of life, pain, and performance status. Smoking in subjects with gastric and lung cancer is also associated with an increased risk of developing second primary tumors. Of particular importance is the evidence that continued smoking is associated with adverse effects during anti-cancer treatment. Smoking also promotes tumor progression and increases resistance to chemotherapy. In addition, continued smoking is related to inferior outcomes of treatment with targeted therapy using erlotinib. The question arises whether an increase in dose of other systemic therapies for lung cancer will result in a clinically significant difference in response or overall outcomes. There are no prospective studies that specifically link smokingmediated induction of the drug metabolism to the therapy efficacy.

Our review summarizes the published literature regarding the influence of smoking as it relates to alterations of the metabolism of systemic therapy in lung cancer. Cigarette smoke can also lead to increased activation of several phase I and II drug-metabolizing enzymes during chemotherapy. Pharmacokinetic and pharmacodynamic interactions between cigarette smoking and systemic chemotherapy for lung cancer may significantly impact the drug clearance, delivery, toxicity, and efficacy.

Studies evaluating the impact of smoking on cancer treatment effectiveness show that continued smoking after the diagnosis of cancer has substantial adverse effects on cancer patients. Several papers report the benefits of smoking cessation and the negative effects of continued smoking on the survival parameters, treatment effectiveness, and quality of life $(4,26)$.

Florou et al. (25) demonstrated the importance of smoking cessation for all cancer patients. There was an increased risk of all-cause mortality and decreased survival, especially for those with smoking-related tumors, such as lung cancer and oral cancer. In subjects with oral cancer, smoking cessation or reduction leads 
to a significant reduction in mortality. There is also evidence that tobacco smoking aggravates and prolongs radiotherapy-induced complications.

Clinical experience indicates that after lung cancer diagnosis, motivation and intention for smoking cessation are greatly increased. However, up to one third of patients continue to smoke after diagnosis or relapse after initial attempts to quit (27). When all studies of the review were analyzed in the short and long term, there was no statistical significance of tobacco smoking cessation intervention in addition to usual care. However, when examining the effect of a multifaceted approach (pharmacological and nonpharmacological) to smoking cessation, the analysis suggested a more positive result.

Zvolska et al. (28) assessed clinical practice guidelines of selected medical professional societies to determine whether or not tobacco dependence treatment recommendations were included. Despite the clinical significance of smoking, there was no mention of smoking in $27.7 \%$ (26/94) of documents related to cardiovascular and respiratory diseases as well as cancer. Only $16 \%(15 / 94)$ of documents listed smoking as a risk factor.

\section{CONCLUSION}

This article reviews the published literature regarding the influence of smoking on alteration of metabolism in systemic therapy of lung cancer. Cigarette smoke can lead to increased activation of several phase I and II drug-metabolizing enzymes also during chemotherapy. Pharmacokinetic and pharmacodynamic interactions between the cigarette smoking and the systemic chemotherapy for lung cancer may impact drug clearance, delivery, toxicity, and efficacy significantly.

The Surgeon General Report highlights 50 years of progress in tobacco control and prevention and presents new data on the health consequences of smoking (29). The 2014 report concludes that smoking by cancer patients and survivors increases overall mortality, cancer-specific mortality, and risk of developing a second primary cancer with further associations with increased cancer recurrence and cancer treatment toxicity. As a result, addressing smoking by cancer patients is increasingly recognized as an essential part of cancer care. Cigarette smoking history should be carefully considered and smoking cessation must be taken into account when designing treatment plans.

\section{Conflict of Interests}

None declared

\section{Funding}

This project was supported by funding from Charles University (PROGRES Q25/LF1).

\section{REFERENCES}

1. Csémy L FA, Kodl M, Skývová M. Tobacco and alcohol use in the Czech Republic 2018. Praha: Státní zdravotní ústav; 2019. (In Czech.)

2. Kroon LA. Drug interactions with smoking. Am J Health Syst Pharm. 2007;64(18):1917-21

3. Hukkanen J. Induction of cytochrome P450 enzymes: a view on human in vivo findings. Expert Rev Clin Pharmacol. 2012;5(5):569-85.
4. O'Malley M, King AN, Conte M, Ellingrod VL, Ramnath N. Effects of cigarette smoking on metabolism and effectiveness of systemic therapy for lung cancer. J Thorac Oncol. 2014;9(7):917-26.

5. Wrighton SA, VandenBranden M, Ring BJ. The human drug metabolizing cytochromes P450. J Pharmacokinet Biopharm. 1996;24(5):461-73.

6. McLemore TL, Adelberg S, Liu MC, McMahon NA, Yu SJ, Hubbard WC, et al. Expression of CYP1A1 gene in patients with lung cancer: evidence for cigarette smoke-induced gene expression in normal lung tissue and for altered gene regulation in primary pulmonary carcinomas. J Natl Cancer Inst. 1990;82(16):1333-9.

7. Palma BB, Silva ESM, Vosmeer CR, Lastdrager J, Rueff J, Vermeulen $\mathrm{NP}$, et al. Functional characterization of eight human cytochrome P450 $1 \mathrm{~A} 2$ gene variants by recombinant protein expression. Pharmacogenomics J. 2010;10(6):478-88.

8. Zhou SF, Wang B, Yang LP, Liu JP. Structure, function, regulation and polymorphism and the clinical significance of human cytochrome P450 1A2. Drug Metab Rev. 2010;42(2):268-354.

9. Zevin S, Benowitz NL. Drug interactions with tobacco smoking. An update. Clin Pharmacokinet. 1999;36(6):425-38.

10. Anzenbacher P, Anzenbacherova E. Cytochromes P450 and metabolism of xenobiotics. Cell Mol Life Sci. 2001;58(5-6):737-47.

11. Buzkova H, Pechandova K, Slanar O, Perlik F. Frequency of single nucleotide polymorphisms of CYP2D6 in the Czech population. Cell Biochem Funct. 2008;26(1):76-81.

12. Guengerich FP. Role of cytochrome P450 enzymes in drug-drug interactions. Adv Pharmacol. 1997;43:7-35.

13. Li J, Bluth MH. Pharmacogenomics of drug metabolizing enzymes and transporters: implications for cancer therapy. Pharmgenomics Pers Med. 2011;4:11-33.

14. Hamilton M, Wolf JL, Rusk J, Beard SE, Clark GM, Witt K, et al. Effects of smoking on the pharmacokinetics of erlotinib. Clin Cancer Res. 2006 Apr 1;12(7 Pt 1):2166-71.

15. Cadranel J, Mauguen A, Faller M, Zalcman G, Buisine MP, Westeel V, et al. Impact of systematic EGFR and KRAS mutation evaluation on progression-free survival and overall survival in patients with advanced non-small-cell lung cancer treated by erlotinib in a French prospective cohort (ERMETIC project - part 2). J Thorac Oncol. 2012;7(10):1490502 .

16. Polychronidou G, Papakotoulas P. Long-Term Treatment with Erlotinib for EGFR Wild-Type Non-Small Cell Lung Cancer: A Case Report. Case Rep Oncol. 2013;6(1):189-96.

17. Yoshioka H, Hotta K, Kiura K, Takigawa N, Hayashi H, Harita S, et al.; Okayama Lung Cancer Study Group. A phase II trial of erlotinib monotherapy in pretreated patients with advanced non-small cell lung cancer who do not possess active EGFR mutations: Okayama Lung Cancer Study Group trial 0705. J Thorac Oncol. 2010 Jan;5(1):99-104.

18. de Graan AJ, Loos WJ, Friberg LE, Baker SD, van der Bol JM, van Doorn L, et al. Influence of smoking on the pharmacokinetics and toxicity profiles of taxane therapy. Clin Cancer Res. 2012 Aug $15 ; 18(16): 4425-32$.

19. van der Bol JM, Mathijssen RH, Loos WJ, Friberg LE, van Schaik $\mathrm{RH}$, de Jonge MJ, et al. Cigarette smoking and irinotecan treatment: pharmacokinetic interaction and effects on neutropenia. J Clin Oncol. 2007;25(19):2719-26.

20. Kanai M, Morita S, Matsumoto S, Nishimura T, Hatano E, Yazumi S, et al. A history of smoking is inversely correlated with the incidence of gemcitabine-induced neutropenia. Ann Oncol. 2009;20(8):1397-401.

21. Hukkanen J, Jacob P, 3rd, Benowitz NL. Metabolism and disposition kinetics of nicotine. Pharmacol Rev. 2005;57(1):79-115.

22. Schuz J, Espina C, Villain P, Herrero R, Leon ME, Minozzi S, et al. European Code against Cancer 4th Edition: 12 ways to reduce your cancer risk. Cancer Epidemiol. 2015;39 Suppl 1:S1-10.

23. Chen J, Jiang R, Garces YI, Jatoi A, Stoddard SM, Sun Z, et al. Prognostic factors for limited-stage small cell lung cancer: a study of 284 patients. Lung Cancer. 2010;67(2):221-6.

24. Zhou W, Heist RS, Liu G, Park S, Neuberg DS, Asomaning K, et al. Smoking cessation before diagnosis and survival in early stage non-small cell lung cancer patients. Lung Cancer. 2006;53(3):375-80.

25. Florou AN, Gkiozos IC, Tsagouli SK, Souliotis KN, Syrigos KN. Clinical significance of smoking cessation in subjects with cancer: a 30-year review. Respir Care. 2014;59(12):1924-36.

26. Condoluci A, Mazzara C, Zoccoli A, Pezzuto A, Tonini G. Impact of smoking on lung cancer treatment effectiveness: a review. Future Oncol. 2016;12(18):2149-61. 
27. Nayan S, Gupta MK, Sommer DD. Evaluating smoking cessation interventions and cessation rates in cancer patients: a systematic review and meta-analysis. ISRN Oncol. 2011;2011:849023.

28. Zvolská K, Fraser K, Zvolský M, Králíková E. Treatment of tobacco Dependence, a Critical Gap in Czech Clinical Practice Guidelines. Cent Eur J Public Health. 2017;25(2):141-4.

29. Warren GW, Alberg AJ, Kraft AS, Cummings KM. The 2014 Surgeon General's report: "The health consequences of smoking - 50 years of progress": a paradigm shift in cancer care. Cancer. 2014;120(13):1914-6.

30. Johnston-Early A, Cohen MH, Minna JD, Paxton LM, Fossieck BE, Jr., Ihde DC, et al. Smoking abstinence and small cell lung cancer survival. An association. JAMA. 1980;244(19):2175-9.

31. Tucker MA, Murray N, Shaw EG, Ettinger DS, Mabry M, Huber MH, et al. Second primary cancers related to smoking and treatment of small-cell lung cancer. Lung Cancer Working Cadre. J Natl Cancer Inst. 1997;89(23):1782-8.

32. Videtic GM, Stitt LW, Dar AR, Kocha WI, Tomiak AT, Truong PT, et al Continued cigarette smoking by patients receiving concurrent chemoradiotherapy for limited-stage small-cell lung cancer is associated with decreased survival. J Clin Oncol. 2003;21(8):1544-9.

33. Garces YI, Yang P, Parkinson J, Zhao X, Wampfler JA, Ebbert JO, et al. The relationship between cigarette smoking and quality of life after lung cancer diagnosis. Chest. 2004;126(6):1733-41.

34. Johnson JR, Cohen M, Sridhara R, Chen YF, Williams GM, Duan J, et al. Approval summary for erlotinib for treatment of patients with locally advanced or metastatic non-small cell lung cancer after failure of at least one prior chemotherapy regimen. Clin Cancer Res. 2005 Sep $15 ; 11(18): 6414-21$
35. Shepherd FA, Rodrigues Pereira J, Ciuleanu T, Tan EH, Hirsh V, Thongprasert $\mathrm{S}$, et al. Erlotinib in previously treated non-small-cell lung cancer. N Engl J Med. 2005;353(2):123-32.

36. Baser S, Shannon VR, Eapen GA, Jimenez CA, Onn A, Lin E, et al. Smoking cessation after diagnosis of lung cancer is associated with a beneficial effect on performance status. Chest. 2006;130(6):1784-90.

37. Clark GM, Zborowski DM, Santabarbara P, Ding K, Whitehead M, Seymour L, et al. Smoking history and epidermal growth factor receptor expression as predictors of survival benefit from erlotinib for patients with non-small-cell lung cancer in the National Cancer Institute of Canada Clinical Trials Group study BR.21. Clin Lung Cancer. 2006;7(6):389-94.

38. Tsao AS, Liu D, Lee JJ, Spitz M, Hong WK. Smoking affects treatment outcome in patients with advanced nonsmall cell lung cancer. Cancer. 2006;106(11):2428-36.

39. Balduyck B, Sardari Nia P, Cogen A, Dockx Y, Lauwers P, Hendriks J, et al. The effect of smoking cessation on quality of life after lung cancer surgery. Eur J Cardiothorac Surg. 2011;40(6):1432-7; discussion 7-8.

40. Weiss JM, Villaruz LC, O'Brien J, Ivanova A, Lee C, Olson JG, et al Results of a Phase II Trial of Carboplatin, Pemetrexed, and Bevacizumab for the Treatment of Never or Former/Light Smoking Patients With Stage IV Non-Small Cell Lung Cancer. Clin Lung Cancer. 2016;17(2):128-32.

Received November 26, 2018 Accepted in revised form November 17, 2019 